\title{
Landsat 8 Observation of the Internal Solitary Waves in the Lombok Strait
}

\author{
I Wayan Gede Astawa Karang ${ }^{1,2}$, Chonnaniyah ${ }^{2}$ and Takahiro Osawa ${ }^{2,3,4}$ \\ ${ }^{1}$ Department of Marine Sciences, Faculty of Marine Science and Fisheries, Udayana University, Bali, Indonesia \\ ${ }^{2}$ Center for Remote Sensing and Ocean Science (CReSOS), Udayana University, Denpasar, Bali, Indonesia \\ ${ }^{3}$ Center for Research and Application of Satellite Remote Sensing (YUCARS), Yamaguchi University, Ube, Japan \\ ${ }^{4}$ Regional Satellite Applications Center for Disaster Management (RSCD), Japan Aerospace Exploration Agency \\ (JAXA), Ube, Japan
}

Received: 2019-01-20 Accepted: 2019-10-14

\author{
Keywords: \\ Internal Solitary Waves, \\ Landsat 8, \\ Lombok Strait \\ Correspondent Email: \\ gedekarang@unud.ac.id
}

\begin{abstract}
Landsat 8, Landsat Data Continuity Mission (LDCM) satellite, was launched on 11 February 2013 with Operation Land Imager (OLI) sensors. This sensor has better radiometric performance than the previous mission, which is quantized in the 12-bit dynamic range due to an increase in the signal-to-noise (SNR) ratio. In this analysis, the spatio-temporal distribution of the propagation of the internal solitary wave (ISW) in the Lombok Strait was extracted from the Landsat 8 images described for the first time. There were 14 ISW events studied for period 2014 - 2015 using Landsat 8. The manifestations of ISW recorded on Landsat 8 images were then extracted using digitization method to investigate and measure several parameters and ISW distribution in the Lombok Strait. The estimation results of the average ISW phase velocity in this study are $2.05 \mathrm{~ms}^{-1}$ with the direction of propagation heading north at an average angle of $19.08^{\circ}$. This study has shown that Landsat 8 can be used to monitor and analyze several internal wave parameters in the ocean.
\end{abstract}

(C) 2019 by the authors. This article is an open access article distributed under the terms and conditions of the Creative Commons Attribution(CC BY NC) licensehttps://creativecommons.org/licenses/by-nc/4.0

\section{Introduction}

Internal Waves (IWs) manifestation using the satellite imagery have been widely studied and analyzed (Apel, 2004). The ability of satellite imagery, both radar and optical imagery, has been used by several researchers to examine the characteristics of IWs in the oceans (Apel et al., 1975; Alpers, 1985; Mitnik, 2000; Susanto et al., 2005; Jackson, 2007; Matthews et al., 2011; Lindsey et al., 2018). Radar imaging by synthetic aperture radar (SAR) is capable of detecting IWs signatures in more detail compared to optical imagery, but the optical images can produce coverage almost every day throughout the world and also can produce some sun-glint images. Optical sensors can also be used for detecting IWs surface manifestation, but the capability is limited to daytime, cloud free, and viewing geometry related to the sun position (Jackson, 2007; Alpers, 2014). Accordingly, optical sensors can be used as a complement to SAR images that have the potential to be used to survey phenomena that occur at sea level on a nearly global scale. Myasoedov (2010) had proven the ability of the optical sensor images to detect the IWs manifestation in the sun-glint area.

Landsat 8 is a continuation of the Landsat mission for the first time into the earth observation satellites since 1972 (Landsat 1). Although Landsat sensors were not designed for aquatic applications, the sun-glint imagery for IWs detection has been previously applied to imagery acquired from Landsat (Apel et al., 1975; Sawyer, 1983). The panchromatic band of Landsat 8 has a spatial resolution of $30 \mathrm{~m}$ and $15 \mathrm{~m}$ with the temporal resolution for 16 days, is a tool that can describe the assessment of IWs in the oceans. Although Landsat 8 imagery has a purpose for land and coastal observations, such as geo-ecology identification (Maulana et al., 2017). Characteristics of Landsat 8 images that have 12-bit sensitivity can interpret the surface more clearly.

IWs characteristics is an important thing to studied because this wave can strongly influence some ocean and coastal activities such as acoustic wave propagation, submarine navigation, and coastal engineering (Klemas, 2012). Lombok Strait is very popular with the IWs intensive characteristics because it has a complex bathymetry and supported by a strong current complexity. Lombok Strait bathymetry is shown in Figure 1, in the northern part of the strait deeper than the middle section. The northern part has a depth of about $1200 \mathrm{~m}$. The Bathymetric contours derived from the General Bathymetric Chart of the Oceans (GEBCO_2014) grid, version 20150318 (http://www. gebco.net) with 30 arc-second resolution. 


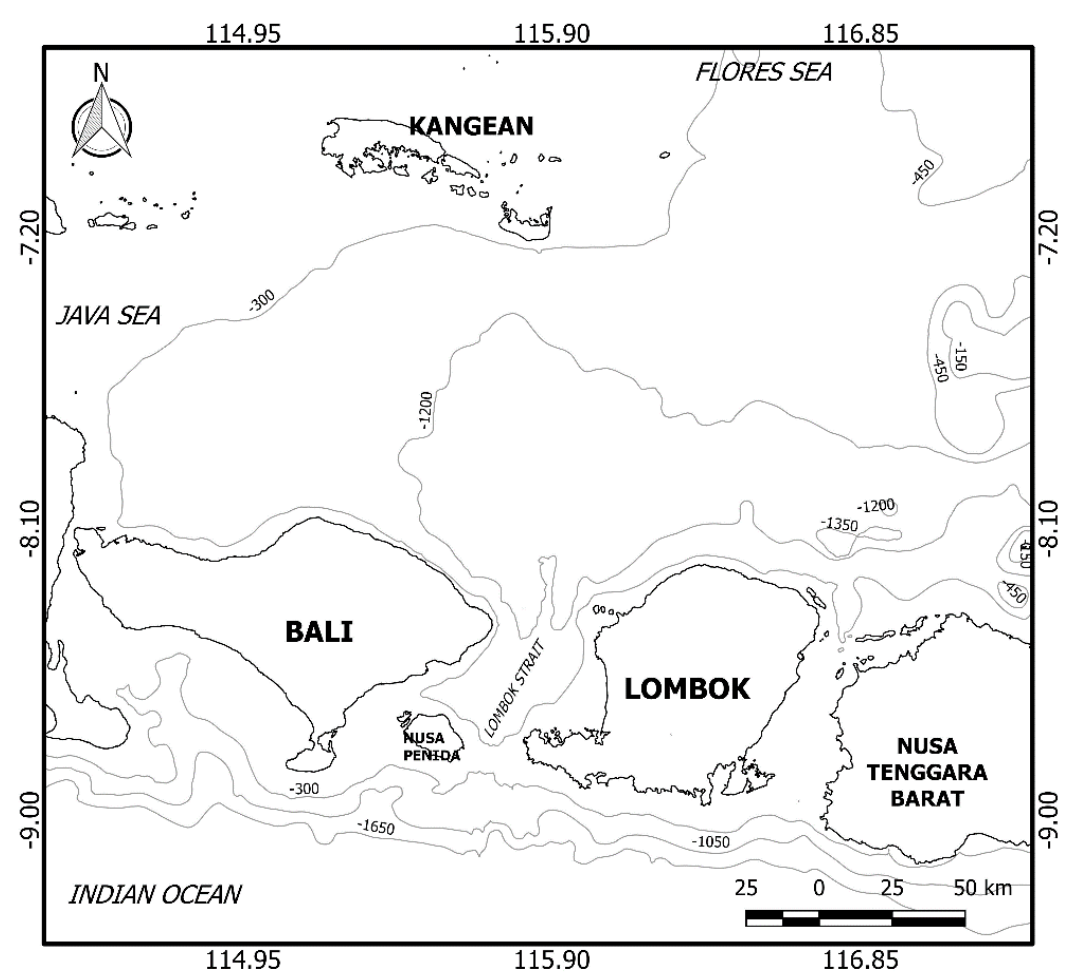

Figure 1. Lombok Strait's bathymetry contours. Depths are displayed in meters.

The sill between the Nusa Penida and the Lombok islands is clearly shown in Figure 1. The sill is approximately $250 \mathrm{~m}$ deep (Susanto et al., 2005). Sill in the Lombok Strait has an important role in the hydrodynamic process in the Lombok Strait and adjacent area. The depth and width of the sill provide the minimum cross-sectional area of the strait, restricting the flow of water through the strait. So that, the great current speeds can generate in this sill.

Satellite imaging for IW observations have been made in the Lombok Strait using either radar or optical sensors (Mitnik et al., 2000; Susanto et al., 2005; Jackson, 2007; Ningsih et al., 2008; Matthews et al., 2011; Karang et al., 2012; Lindsey et al., 2018). Previous studies of IWs have been conducted on SAR images in the Lombok Strait (Karang \& Nishio, 2011; Karang et al., 2012; Mitnik et al., 2000; Susanto et al., 2005). These studies described the use of SAR imaging for the detection, estimation of parameters, and spatio-temporal distribution of IWs in the Lombok strait. Observation of the Lombok Strait IWs using optical imagery also has been studied by using geostationary satellite.. The latest research uses Himawari-8 geostationary satellite provides the capability to estimate some IWs parameters (Lindsey et al., 2018; Karang, Connaniyah, and Osawa 2019). The use of Landsat imagery for IWs observation have been done in the various location globally (Kim et al., 2018; Lavrova et al., 2016; Osadchiev, 2018), however there is no IWs study using Landsat imagery have been reported in the Indonesian seas. In this study, the ISWs characteristic and parameter estimation using Landsat
8 has been observed and analyzed for the first time in the Lombok Strait.

\section{The Methods}

\section{Satellite Images and Pre-Processing}

Landsat 8 is the newest satellite in the Landsat program,, has a sensor Onboard Operational Land Imager (OLI) and the Thermal Infrared Sensor (TIRS) consist of 9 medium-spatial resolution (30 meters) spectral bands for bands 1 to 7 and 9. The ultra-blue Band 1 is advantageous for aerosol and coastal research. Band 8 is panchromatic band with about 15 meters spatial resolution. The spatial resolution of thermal infrared Band 10 and 11 are 100 meters. Band 1-9 are on the OLI sensor and Band 10-11 are on TIRS sensor.

Landsat 8 takes 99 minutes to orbit the Earth and has a temporal resolution for 16 days. The advantage of Landsat 8 data from previous generations is the gray level (Digital Number-DN) which previously ranges from 0-256, now has a gray level of 0-4096. There is an increase in sensitivity to each pixel that originally has 8-bit quantification, increased to 12-bit. Improvement in makes the process of interpretation of objects on the surface becomes easier. IWs that can be detected through surface roughness patterns can be interpreted better with this increased sensitivity. A better sensitivity is needed to observe the surface roughness variability in more details (Chander et al., 2009).

The Landsat 8 OLI images were taken from the United States Geological Survey (USGS) Data Center 
(https://earthexplorer.usgs.gov/). Landsat 8 OLI/TIRS C1 Level - 1 data, where the geometric correction has been improved the accuracy using DEM topographic maps (Zanter, 2015), was used in this study. The composite Landsat 8 Bands $5(850-880 \mathrm{~nm}$ at $30 \mathrm{~m}$ resolution), $4(630-670 \mathrm{~nm}$ at $30 \mathrm{~m}$ resolution) and 3 $(530-590 \mathrm{~nm}$ at $30 \mathrm{~m}$ resolution) into the red, green and blue image channels respectively is used to create false-color images.. Full detail of the characteristics of Landsat 8 data products is given in Table 1 .

There are 14 Landsat 8 images of Lombok Strait area with cloud cover less than $10 \%$ were used for this study (Table 2). To cover the entire area of the Lombok Strait, we used two frames of Landsat 8 images as in Figure 2 to observe the ISW detection in this area.

Tabel 1. The characteristics of Landsat 8

\begin{tabular}{|c|c|c|c|c|c|}
\hline Sensor & $\begin{array}{c}\text { Band } \\
\text { Number }\end{array}$ & $\begin{array}{l}\text { Band } \\
\text { Name }\end{array}$ & Wavelength (nm) & $\begin{array}{l}\text { Resolution } \\
(\mathrm{m})\end{array}$ & Band Applications \\
\hline \multirow[t]{9}{*}{ OLI } & 1 & Coastal & $430-450$ & 30 & Research of the coast and aerosols \\
\hline & 2 & Blue & $450-510$ & 30 & $\begin{array}{l}\text { Bathymetrical mapping, distinguishing } \\
\text { soil from vegetation, and deciduous from } \\
\text { coniferous vegetation }\end{array}$ \\
\hline & 3 & Green & $530-590$ & 30 & $\begin{array}{l}\text { Emphasizes peak vegetation, which is useful } \\
\text { for plant vigor assessmen }\end{array}$ \\
\hline & 4 & Red & $630-670$ & 30 & Discriminates of vegetation slopes \\
\hline & 5 & NIR & $850-880$ & 30 & $\begin{array}{l}\text { Emphasizes the content of biomass and the } \\
\text { shorelines }\end{array}$ \\
\hline & 6 & SWIR 1 & $1570-1650$ & 30 & $\begin{array}{l}\text { Discriminates soil and vegetation moisture } \\
\text { content; penetrates thin clouds }\end{array}$ \\
\hline & 7 & SWIR 2 & $2110-2290$ & 30 & $\begin{array}{l}\text { Improved soil and vegetation moisture and } \\
\text { thin cloud penetration }\end{array}$ \\
\hline & 8 & Pan & $500-680$ & 15 & Sharper image definition \\
\hline & 9 & Cirrus & $1360-1380$ & 30 & $\begin{array}{l}\text { Improved detection of contamination of } \\
\text { cirrus cloud }\end{array}$ \\
\hline \multirow[t]{2}{*}{ TIRS } & 10 & TIRS 1 & $10600-11190$ & 100 & $\begin{array}{l}\text { Thermal mapping and soil moisture } \\
\text { estimation }\end{array}$ \\
\hline & 11 & TIRS 2 & $11500-12510$ & 100 & $\begin{array}{l}\text { Thermal mapping and soil moisture } \\
\text { estimation }\end{array}$ \\
\hline
\end{tabular}

Table 2. Landsat 8 Dataset for ISW observation in the Lombok Strait area

\begin{tabular}{lllllll}
\hline Coordinate & \multicolumn{1}{c}{ Date } & & ID & $\begin{array}{c}\text { Scene } \\
\text { Center } \\
\text { Time }\end{array}$ & Scene Center Coordinate \\
& & & & & South & East \\
\hline Path & Row & & & & & \\
\hline 116 & 65 & 30 May 2014 & LC81160652014150LGN00 & $02: 22: 59$ & -7.234110 & 116.201249 \\
116 & 66 & 30 May 2014 (Near Sill) & LC81160662014150LGN00 & $02: 23: 23$ & -8.679420 & 115.889399 \\
116 & 65 & 28 April 2014 & LC81160652014118LGN00 & $02: 23: 12$ & -7.232760 & 116.1918 \\
116 & 66 & 28 April 2014 (Near Sill) & LC81160662014118LGN00 & $02: 23: 35$ & -8.679420 & 115.88265 \\
116 & 66 & 1 July 2014 & LC81160662014182LGN00 & $02: 23: 34$ & -8.679408 & 115.892096 \\
116 & 65 & 22 November 2014 & LC81160652014326LGN00 & $02: 23: 33$ & -7.232760 & 116.208 \\
116 & 66 & 22 November 2014 (Near & LC81160662014326LGN00 & $02: 23: 57$ & -8.679420 & 115.8948 \\
116 & 65 & 17 May 2015 & LC81160652015137LGN00 & $02: 22: 25$ & -7.232760 & 116.18343 \\
116 & 66 & 17 May 2015 (Near Sill) & LC81160662015137LGN00 & $02: 22: 49$ & -8.679420 & 115.870230 \\
116 & 66 & 4 July 2015 & LC81160662015185LGN00 & $02: 23: 14$ & -8.679420 & 115.878330 \\
116 & 66 & 5 August 2015 & LC81160662015217LGN00 & $02: 23: 25$ & -8.67807 & 115.896150 \\
116 & 65 & 6 September 2015 & LC81160652015249LGN00 & $02: 23: 14$ & -7.232760 & 116.2026 \\
116 & 66 & 6 September 2015 (Near Sill) & LC81160662015249LGN00 & $02: 23: 38$ & -8.679420 & 115.89345 \\
116 & 66 & 24 October 2015 & LC81160662015297LGN00 & $02: 23: 52$ & -8.679420 & 115.884 \\
\hline
\end{tabular}




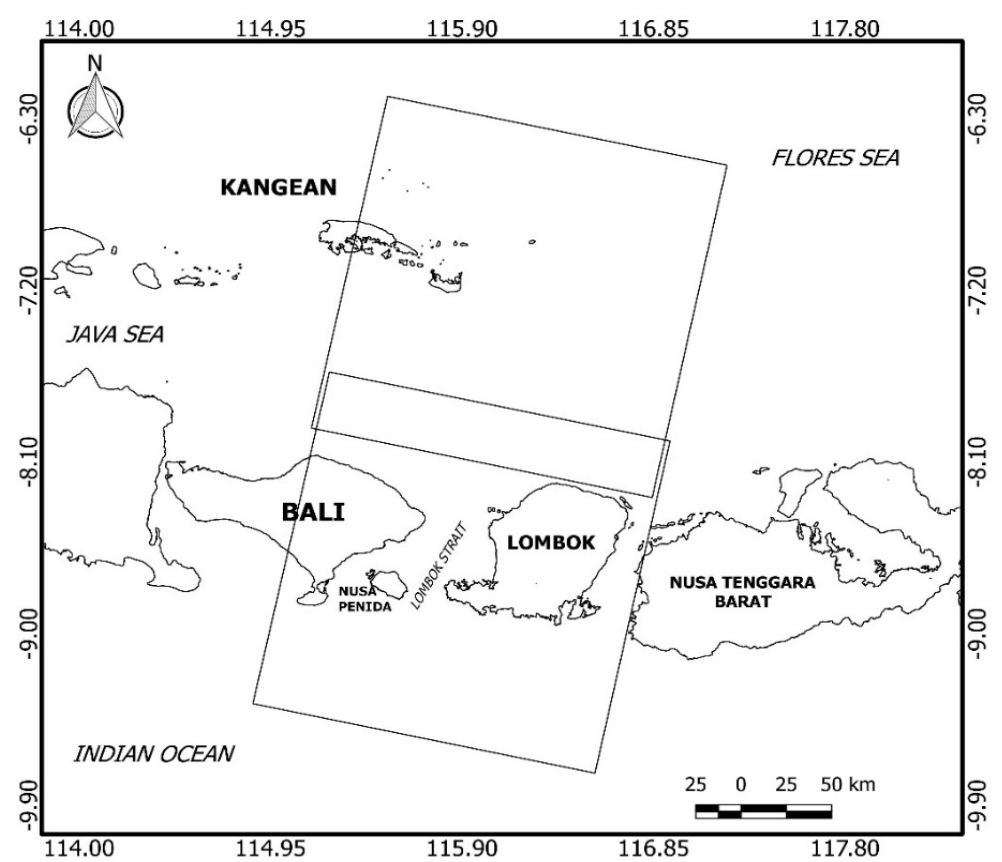

Figure 2. Landsat 8 imagery frame for Lombok Strait area

\section{ISW Propagation Direction Extraction}

IWs can disturb the hydrodynamic mechanism in the Lombok Strait, so the evolution and propagation of IWs that occur in this area are very important to study. ISW in the Lombok strait propagate to the northern and southern part of the sill, but when this wave is on the outside of the strait there is a wave deflection at a certain angle. Gao et al., (2018) introduces the extraction method of the ISW propagation direction from first-crest of the wave packet. This method is used to determine the propagation direction of ISW on Himawari-8 geostationary satellite in the South China Sea.

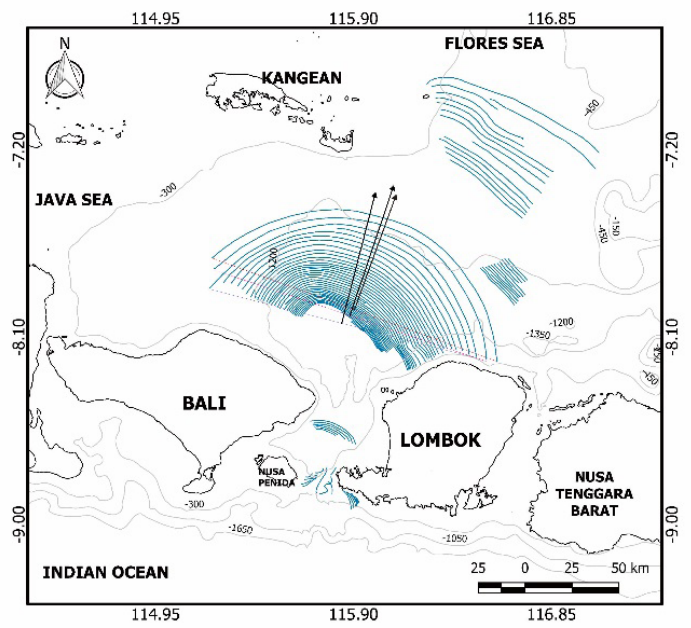

(a)

Figure 3. (a) ISWs extraction in the study area. The bathymetric isobaths represented by the gray contours. Each curve represents the ISW first-crest observed by Landsat 8 images. The black lines are ISW propagation direction. (b) ISW propagation direction extraction method.
Figure 3(a) shows the sketch of the propagation direction extraction for ISW in the Lombok strait. There is a difference in angular direction formed by each wave in one packet. The estimation method of IWs propagation direction is described by Figure 3(b). The first-crest of ISW is represented by AB curve, the center point of the line $\mathrm{AB}$ (straight) is represented by point $\mathrm{C}$, and the transect line $\mathrm{CD}$ is perpendicular to line $\mathrm{AB}$ (straight). The angle ("a") between the transect line and the North lines is the ISW propagation path estimate product.

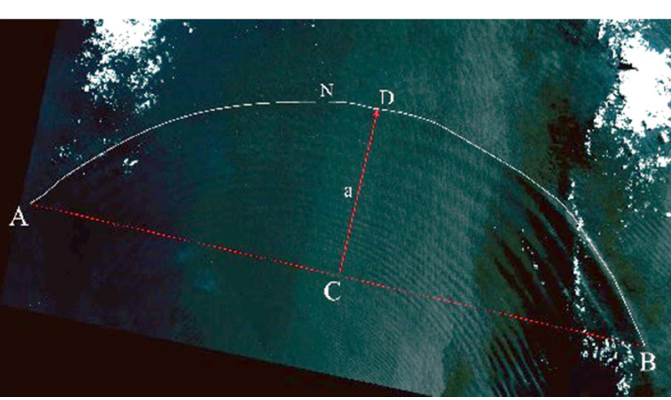

(b) 


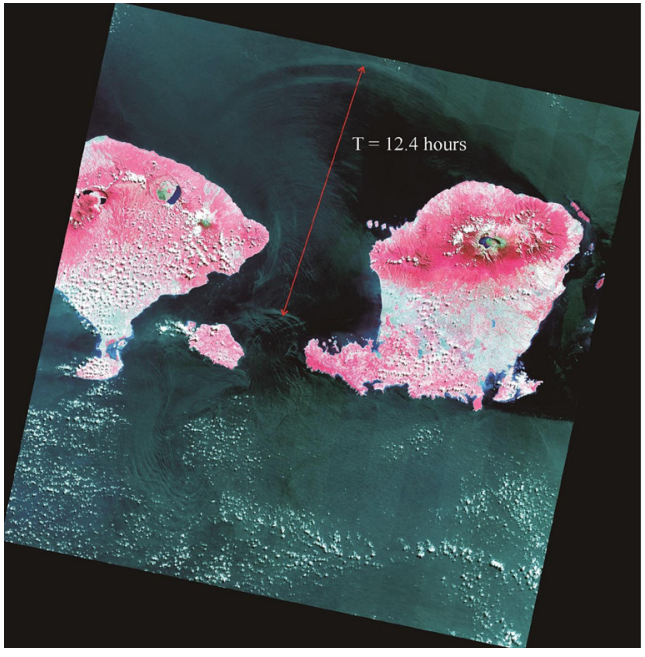

(a)

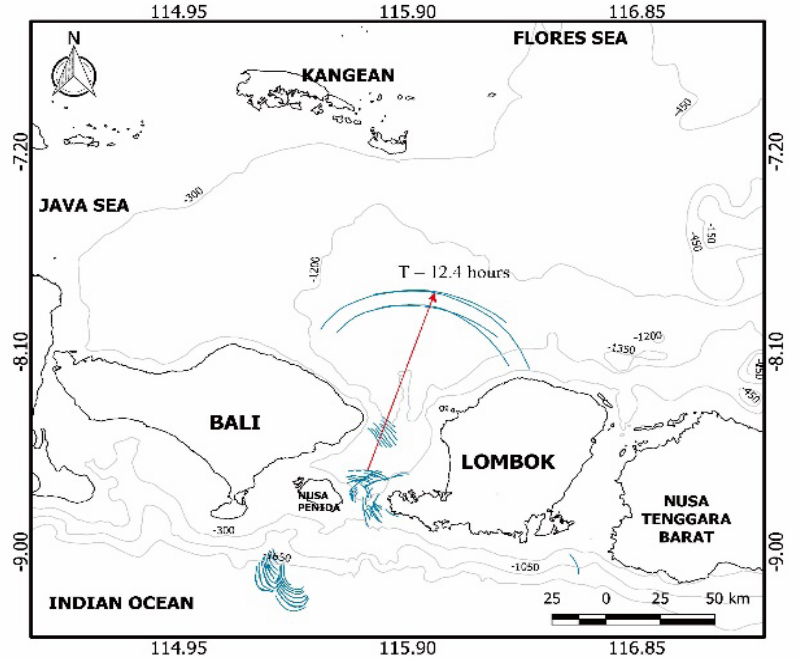

(b)

Figure 4. Phase speed calculation, (a) Landsat 8 image acquired on 17 May 2015 and

(b) ISW extraction result sketch

\section{ISW Phase Speed Calculation}

Estimation of the ISWs phase speed can be calculated using one scene of satellite image that containing two ISW packets (Figure 4). This method assumes that the time difference between two adjacent ISW packet is a local tidal period (Porter \& Thompson, 1999). Porter \& Thompson (1999) measured the ISW phase speed by dividing the spatial gap with the local tidal cycle between neighboring ISW crest.. In this paper, we used Porter \& Thompson (1999) method to estimate the ISW phase speed in the Lombok Strait using Landsat 8 satellite images with the local tidal period assumption is the semidiurnal tidal period (12.42 h).

\section{Result and Discussion}

\section{Landsat 8 Signatures of Internal Waves}

IWs surface manifestation on satellite images seen as bright and dark bands which are the result of variations in sea surface roughness (Alpers, 1985). Variations in sea surface roughness can be due to a converging pattern (coarse) and divergent (smooth) as a result of the current activities IWs below the sea surface layer (Munk et al., 2000). IWs first-crest manifestation in the satellite images seen as rank-ordered bright lines. In optical images, ISW manifestations on the surface can be seen in the sun-glint region. ISW manifestations in the sun-glint region depends on the surface wave spectrum modulation induced by ISW activity below sea level. Optical imaging depends heavily on viewing geometry (Liu et al., 2014).
ISW characteristics in the Lombok Strait has been described by Matthews et al. (2011) using SAR imagery and numerical modeling and its relation to monsoon conditions. The results of this study have identified two types of ISW generated in the Lombok Strait, the first type is a wave that propagates to the northern part of the generation site is known as arc-like IWS (AIWs). The second type is a wave that propagates to the southern part of the Lombok Strait which has an irregular shape which is then called irregular-IWs (IIWs). This irregular shape generated when there is an extensive flow towards the south of the strait which causes a distorted thermal plume, a group of braids with an incompatible orientation with a uniform outflow motion from the sill (Matthews et al., 2011). Landsat 8 imagery data used in this study also observed similar types of IWs propagation that propagate as arc-like to north and irregular shape to south of the Lombok Strait.

The Landsat 8 image of 5 August 2015 (Figure 5a) showed two packets of IWs propagating north into the Flores Sea and south into the Indian Ocean. Pixel intensity extracted from the DN of Landsat 8 (Figure $5 b$ ) increasing along the IWs packet due to sea surface roughness variation induce by IWs activities. The distance between the northward packet to the sill is about $74.68 \mathrm{~km}$ and the distance between the southward packet to the sill is about $52.23 \mathrm{~km}$. The type of wave packet that propagates to the north is the AIW and that propagates to the south has a type of IIW. The wave packets that are near the sill have an irregular shape (IIW type), but during the propagation to the deeper bathymetry this wave will change to the arc-like type. 


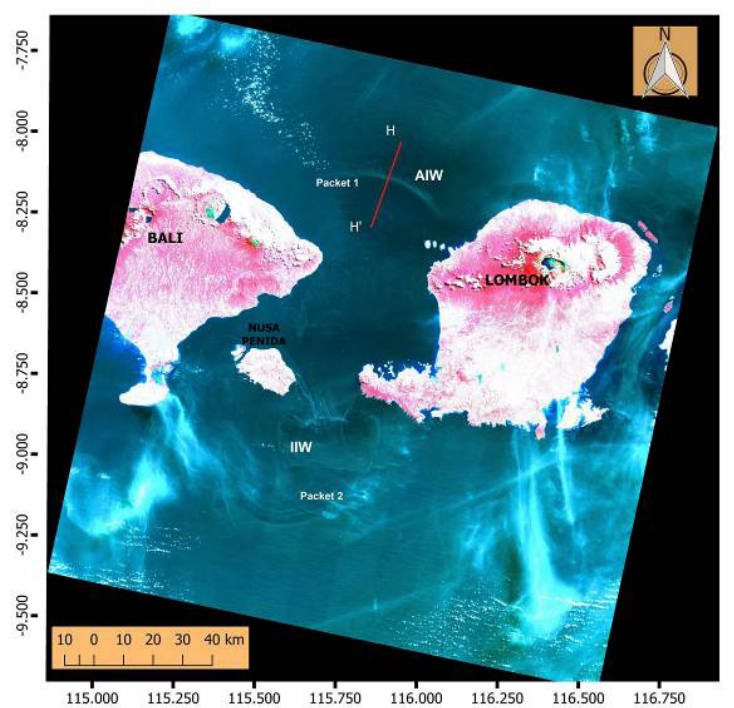

(a)

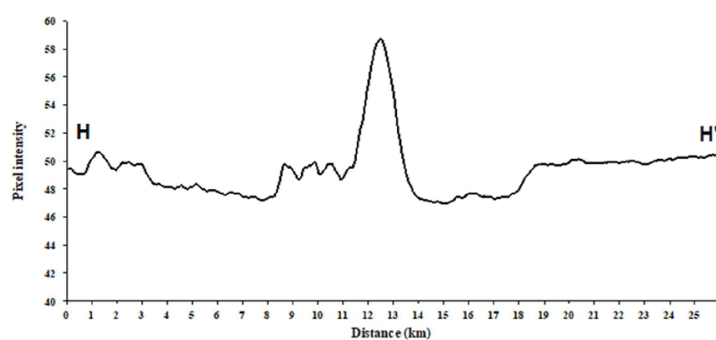

(b)

Figure 5. (a) Landsat 8 image of the Lombok Strait area acquired on 5 August 2015 at 02:23:25 UTC.

(b) Pixel intensity cross-profile plot along sections marked by a red line in HH'.

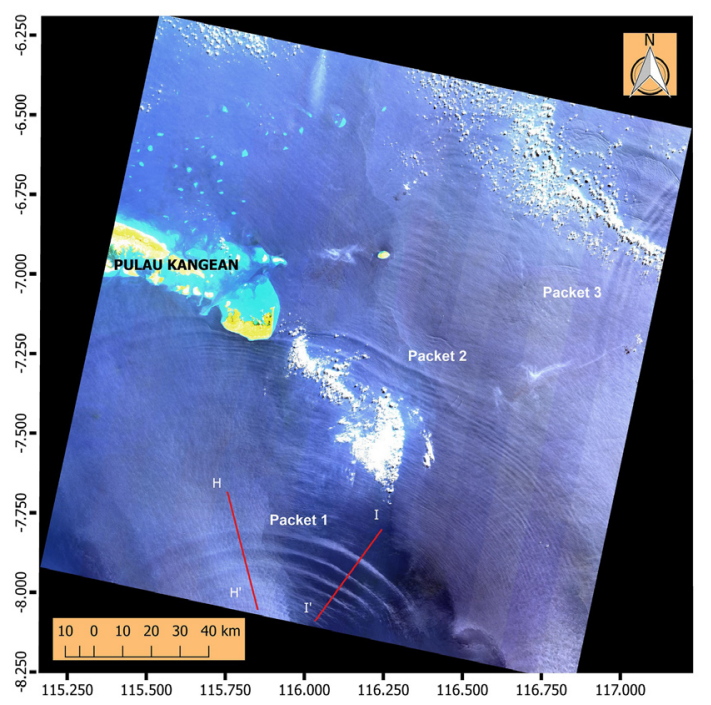

(a)

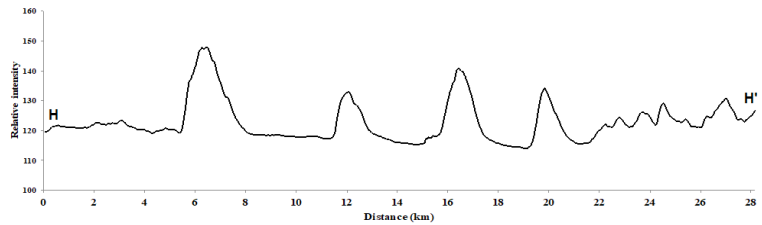

(b)

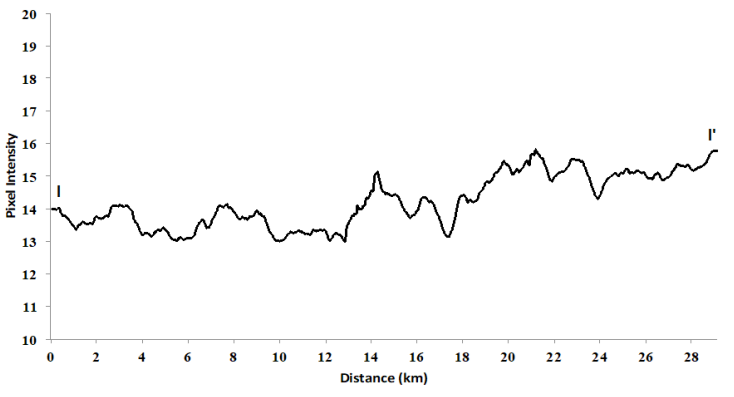

(c)

Figure 6. (a) (a) Landsat 8 image of the Lombok Strait area recorded on 30 May 2014 at 02:22:59 UTC. (b) Pixel intensity cross-profile plot along sections marked with a red line in $\mathrm{HH}^{\prime}$ and, (c) Pixel intensity cross-profile plot along sections marked with a red line in II'

Figure 6 (a) shows the three packets of IWs detected by the Landsat 8 image acquired on 30 May 2014. Packet 2 crashed into the shallow water near the Kangean Islands, with the distance about 200 $\mathrm{km}$ from the sill. The northward packet wavelengths decrease from the front to the rear approximately 4 - $10 \mathrm{~km}$ (Figure 6b). Meanwhile Figure 6c shows the influence of different sunglint conditions on Landsat 8 responses in recording IWs where the pixel intensity variation does not show a strong difference between front and rear. Before reaching the Kangean Islands this wave (Packet 1) has AIW type, but after passing the islands this wave (Packet 2) will break and have an irregular shape and then still passing through the islands. Another interesting phenomenon in Figure 6 is the detection of the wave packet (Packet 3 ) that has a direction perpendicular to the wave packets that coming from the Lombok Strait.

\section{ISWs Spatial-Temporal Distribution and Propagation Direction}

A selection of 14 Landsat 8 images were to analyze the temporal and spatial distribution of Lombok Strait was selected. Spatio-temporal distribution map was created by overlaying all these ISW packets extraction 
(Figure 7). The observation result shows that the ISW distribution is spread in the southern and northern parts of the Lombok strait and the generation site is in the shallow sill between the islands of Nusa Penida and Lombok. This observation results shows that the ISW packets have a refraction characteristic. Figure 8 shows that in both directions of ISW packets (north and south) is deflected. This can occur because of the effect of depth change. The crest of the ISW packet in the shallower areas will have smaller speeds than the deeper depth. Consequently, the wave crest will bend and attempt to parallel with the depth contour.
The Landsat 8 images were used as a baseline for temporal variability of the ISW in the Lombok strait. Figure 8 shows that ISW was detected on Landsat 8 are distributed only in certain months. Based on images collected over period of 2014 to 2015, it appears that ISW is detected on Landsat 8 only in May, July, August, September, October, and November.

The partial propagation of the Lombok Strait ISW is derived on the basis of the procedure for extracting the propagation direction of ISWs in Secion 2.. The ISW parameters estimation of nineteen packets is listed in Table 3.

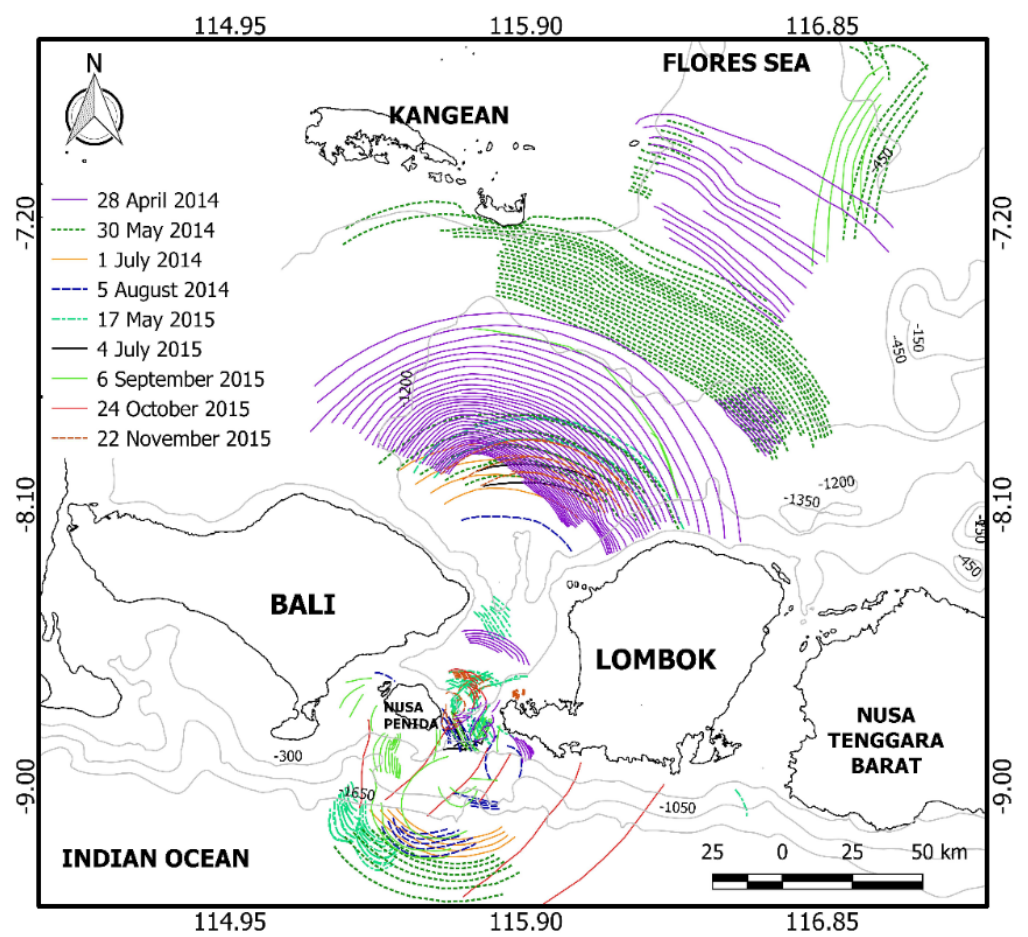

Figure 7. Spatio-temporal distribution map of ISWs extraction in the study area by Landsat 8 images during April 2014 to November 2015

Table 3. Dynamical parameters of northward and southward propagating ISWs in the Lombok strait, estimated using Landsat 8 images.

\begin{tabular}{lcccc}
\hline \multicolumn{1}{c}{ Date } & Soliton Packet & $\begin{array}{c}\text { Number of Solitons in } \\
\text { a Packet }\end{array}$ & $\begin{array}{c}\text { Propagation } \\
\text { Direction }\end{array}$ & Depth \\
\hline Northward (in the Lombok Strait area) & 13 & & 1200 \\
\hline 28 April 2014 & Packet 1 & $30-32$ & $21.24^{\circ}$ & 1350 \\
& 2 & 6 & $20.30^{\circ}$ & 1200 \\
30 May 2014 & Packet 2 & 3 & $27.04^{\circ}$ & 1200 \\
& Packet 1 & 5 & $30.40^{\circ}$ & 1350 \\
1 July 2014 & Packet 1 & 4 & $17.98^{\circ}$ & 1350 \\
22 November 2014 & Packet 1 & 3 & $6.29^{\circ}$ & 1350 \\
17 May 2015 & Packet 1 & 2 & $12.91^{\circ}$ & 1350 \\
4 July 2015 & Packet 1 & 2 & $12.47^{\circ}$ & 1350 \\
5 August 2015 & Packet 2 & 1 & $4.66^{\circ}$ & 1350 \\
6 September 2015 & & 1 & $17.31^{\circ}$ & 1350
\end{tabular}


Average azimuth

Northward (in the Flores Sea)

30 May 2014

6 September 2015

Packet 1

Packet 1

Average azimuth

Southward

30 May 2014

1 July 2014

17 May 2015

5 August 2015

6 September 2015

24 October 2015

Average azimuth

Packet 4

Packet 2

Packet 2

Packet 2

Packet 3

Packet 1 $19.08^{\circ}$

$295.58^{\circ}$

450

$289.30^{\circ}$

1200

$292.44^{\circ}$ $195.68^{\circ}$

1650

$190.51^{\circ}$

1650

$202.02^{\circ}$

1650

$190.37^{\circ}$

1650

$226.96^{\circ}$

1650

$130.62^{\circ}$

$189.36^{\circ}$
The results of the propagation direction estimation in Table 2 for the Landsat 8 image acquired on 28 April 2014 (Figure 8) show the characteristics of ISW as a propagating wave. ISW packets were detected on this image consists of three packets that are scattered in the northern part of the strait. When the detected ISW packet is near the generation site, this wave packet has 6 solitons with the average propagation angle are $27.04^{\circ}$ at a depth of about $1200 \mathrm{~m}$. The second ISW packets are at a depth of about $1350 \mathrm{~m}$ having about 30 solitons with the average propagation angle are $20.30^{\circ}$. Increasing depth causes the number of packets detected to increase and the propagation direction of this second wave packets changes. The third ISW packets in the Flores Sea has smaller soliton number than the second ISW packets. These packets are located in shallower water than the second packets and the propagation direction is deflected due to depth change.

Characteristics of the Lombok Strait based on the result of spatial distribution analysis indicate that ISW packet will be detected in deep waters and the propagation direction will be deflected parallel to the bathymetry contour change. The results also show that the number of solitons in one packets is found to increase in the deeper waters.

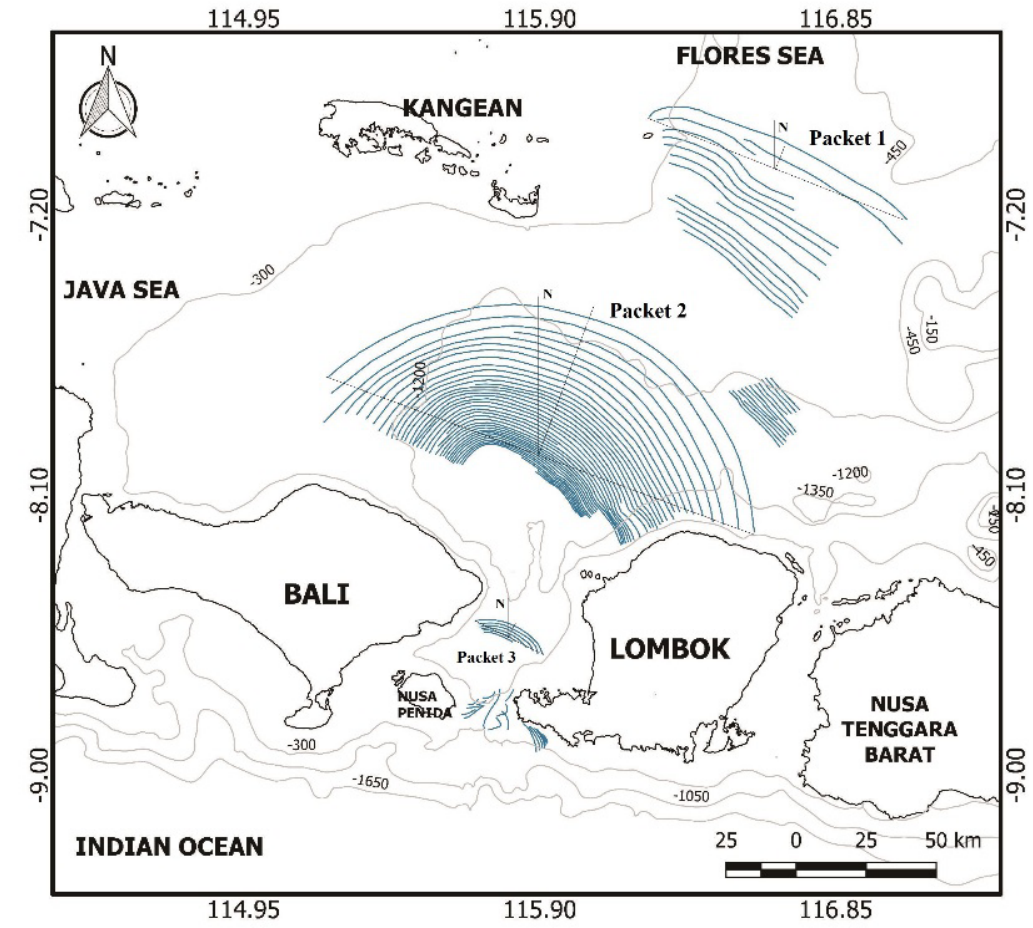

Figure 8. Sketch of ISW packets propagation angle estimation results by Landsat 8 images acquired on 28 April 2014 overlaid with bathymetric contour. 


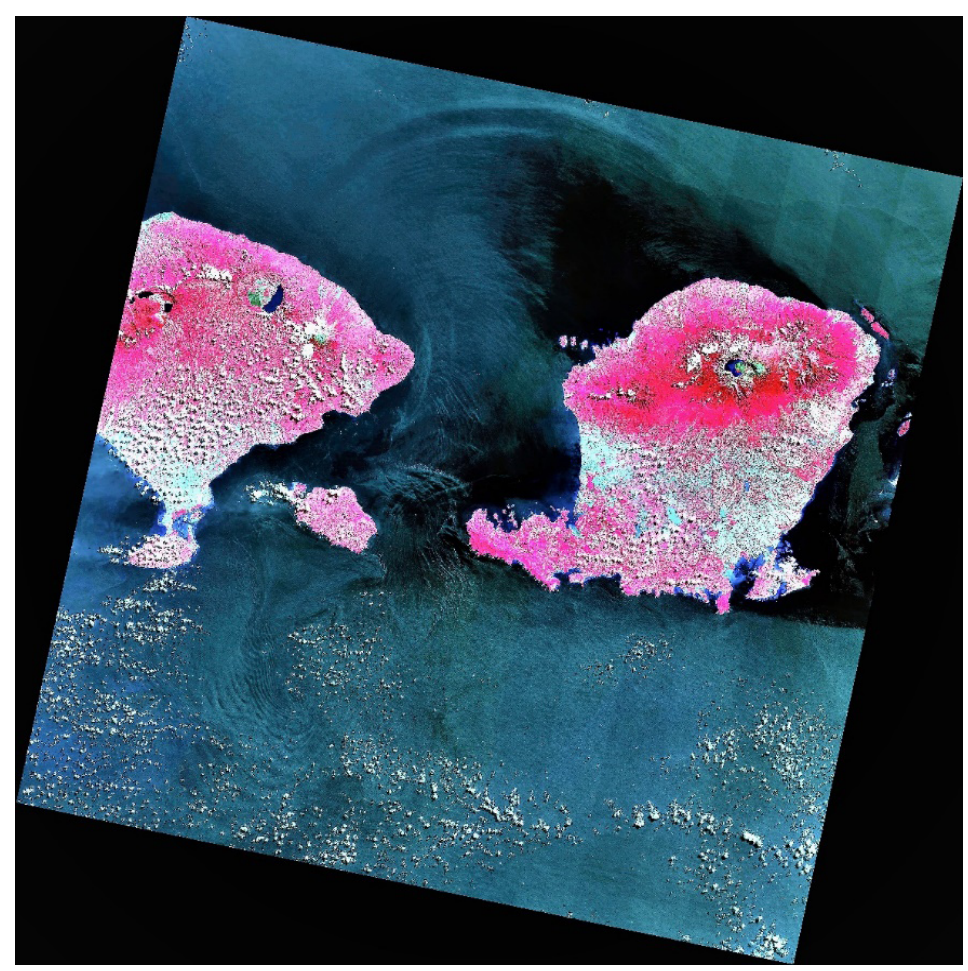

Figure 9. Landsat 8 images of the Lombok Strait area acquired on 17 May 2015 at 02:22:49 UTC

\section{Phase Speed of ISWs}

ISW phase speeds can be estimated using one satellite image containing two packets ISWs and calculated using the Porter \& Thompson (1999) methods. Susanto et al. (2005) calculated the dynamical parameters of the northward-propagating ISW in the Lombok strait by analyzing two consecutive SAR images acquired on 23 and 24 April 1996. They reported the average ISW-train phase speeds in the Lombok Strait is $1.96 \mathrm{~ms}-1$, the average wavelength is about $3.8 \mathrm{~km}$, and solitons in a packet are about 23 . Ningsih et al. (2008) showed the numerical simulation result of the northward-propagating ISW-train phase speeds are about $0.71-2.67 \mathrm{~ms}-1$ and the southwardpropagating are about $0.21-1.53 \mathrm{~ms}-1$. Using ALOS PALSAR images, Mitnik (2008) defined the northward propagating ISW-train mean phase speeds between 2 packets ISW about 1.6 to $2.3 \mathrm{~ms}-1$ by measuring the distances between the leading signals in adjacent wave packets generated $12.4 \mathrm{~h}$ apart.

Figure 9, the Landsat 8 image of 17 May 2015, shows two packets of ISWs propagating to the northern part of the strait into the Flores Sea. The crest to crest distance of packets 1 and packet 2 is $\sim 91.77 \mathrm{~km}$. The phase speed estimation are calculated by comparing the crest to crest distance with the semidiurnal tidal period ( $\mathrm{T}=12.42$ hours). The phase speed estimation result is $2.05 \mathrm{~ms}-1$. The results of this estimate are in good agreement with the result of previous investigation by Susanto et al. (2005), Ningsih et al. (2008), and Mitnik (2008).

\section{Conclusion}

The characteristics of the Lombok Strait ISW, such as the direction of propagation and phase velocity and their relation to the bathymetry, has been observed using Landsat 8 imagery. The observation results could confirm the suggestion by the previous researcher (Matthews et al., 2011; Ningsih et al., 2008; Susanto et al., 2005) about the phase speeds and spatial distribution in the observation area.

Estimation results of ISW propagation direction using a simple extraction method (Gao et al., 2018), indicate a propagation direction bend. The angular magnitude resulting from this calculation has confirmed and clarified the occurrence of wave refraction characteristics. This can occur because of the effect of depth change. The crest of the ISW packet in the shallower areas will have smaller speeds than the deeper depth. Consequently, the wave crest will bend and attempt to parallel with the depth contour. The phase speeds calculation result using the spatial difference between the two first-crests in one image and assumed the time interval to be the semidiurnal tidal period about $2.05 \mathrm{~ms}-1$.

\section{Acknowledgements}

Wewould like to thank the United States Geological Survey (USGS) Data Center (https://earthexplorer.usgs. gov/) for access Landsat 8 imagery and GEBCO (http:// www.gebco.net) for access Lombok Strait bathymetry data. This paper is supported by USAID through Sustainable Higher Education Research Alliances 
(SHERA) Program - Center for Collaborative Research Animal Biotechnology and Coral Reef Fisheries (CCR ANBIOCORE).

\section{References}

Alpers, W. (1985). Theory of Radar Imaging of Internal Waves. Nature, 314(No. 6008), 245-247.

Alpers, W. (2014). Ocean Internal Waves. In Njoku, E. G. Encyclopedia of Remote Sensing. 433-437. Springer Reference. New York.

Apel, J. R., Byrne, H. M., Proni, J. R., \& Charnell, R. L. (1975). Observations of oceanic internal and surface waves from the Earth Resources Technology Satellite. Journal of Geophysical Research, 80(6).

Apel, J. R. (2004). Oceanic Internal Waves and Solitons. In Jackson, C. R. and Apel, R. Synthetic Aperture Radar Marine User's Manual. NOAA/ NESDIS, Washington DC., 189-206.

Chander, G., Markham, B.L., Helder, D.L. (2009). Summary of current radiometric calibration coefficients for Landsat MSS, TM, ETM+, and EO-1 ALI sensors. Remote Sens. Environ., 113, 893-903

Gao, Q., Dong, D., Yang, X., Husi, L., \& Shang, H. (2018). Himawari-8 Geostationary Satellite Observation of The Internal Solitary Waves In The South China Sea. In The International Archives of the Photogrammetry, Remote Sensing and Spatial Information Sciences (Vol. XLII, pp. 7-10). Beijing, China.

Jackson, C. (2007). Internal wave detection using the Moderate Resolution Imaging Spectroradiometer (MODIS). Journal of Geophysical Research. 112(C11), C11012. https://doi.org/10.1029/2007JC004220.

Karang, I. W. G. A., \& Nishio, F. (2011). Internal waves in the Lombok Strait revealed by ALOS PALSAR images. In IEEE Intern Geosci.Remote Sensing Symp. IGARSS 2011 (Vol. 17, pp. 253-256). Vancouver, Canada.

Karang, I. W. G. A., Nishio, F., Mitnik, L., \& Osawa, T. (2012). Spatial-Temporal Distribution and Characteristics of Internal Waves in the Lombok Strait Area Studied by Alos-Palsar Images. Earth Science Research, 1(2), 11-22. https://doi.org/10.5539/esr.v1n2p11.

Karang, I. W. G. A., Chonnaniyah \& Osawa, T. (2019). Internal solitary wave observations in the Flores Sea using the Himawari-8geostationarysatellite.InternationalJournalof Remote ensing, DOI: $10.1080 / 01431161.2019 .1693079$

Kim, H., Son, B. Y., Jeong, J-Y., and Jo, Y-H. (2018). Comparison of Internal Waves in Various Ocean Fields Around the Korean Peninsula. Journal of Coastal Research: Special Issue 85 - Proceedings of the 15th International Coastal Symposium. 466-470.

Klemas, V. (2012). Remote Sensing of Ocean Internal Waves: An Overview. Journal of Coastal Research, 282(May 2012), 540-546. https://doi.org/10.2112/JCOASTRESD-11-00156.1.

Lavrova, O. Y., Soloviev, D. M., Strochkov, M. A., Bocharova, T. Y. (2016). River plumes investigation using Sentinel2A MSI and Landsat-8 OLI data. Proc. SPIE 9999, Remote Sensing of the Ocean, Sea Ice, Coastal Waters, and Large Water Regions 2016, 99990G. https://doi. org/10.1117/12.2241312.
Lindsey, D. T., Nam, S. H., \& Miller, S. D. (2018). Tracking oceanic nonlinear internal waves in the Indonesian seas from geostationary orbit. Remote Sensing of Environment, 208, 202-209.

Liu, B., Yang, H., Ding, X., \& Li, X. (2014). Tracking the internal waves in the South China Sea with environmental satellite sun glint images. Remote Sensing Letters, 5(7), 609-618. https://doi.org/10.1080/2150704X.2014.949365

Matthews, J. P., Aiki, H., Masuda, S., Awaji, T., \& Ishikawa, Y. (2011). Monsoon regulation of Lombok Strait internal waves. Journal of Geophysical Research: Oceans, 116(5), 1-14. https://doi.org/10.1029/2010JC006403

Maulana, E., Wulan, T. R., Wahyunungsih, D. S., Ibrahim, F., Putra, A. S., \& Putra, M. D. (2017). Geoecology Identification Using Landsat 8 for Spatial Planning in North Sulawesi Coastal. Indonesian Journal of Geography, 49(2), 212-217. https://doi.org/http://dx.doi. org/10.22146/ijg.13189

Mitnik, L., Alpers, W., Hock, L., Branch, F. E., \& Road, L. K. (2000). Thermal Plumes and Internal Solitary Waves Generated. In ERS-Envisat Symposium: Looking down to Earth in the New Millenium. Gothenburg, Sweden: European Space Agency, Publication Division, Noordwijk, The Netherlands.

Mitnik, Leonid. (2008). Advanced Land Observing Satellite PALSAR Observations of the Oceanic Dynamic Phenomena in the Coastal Zone. International Geoscience and Remote Sensing Symposium (IGARSS). 2. 351-354. 10.1109/IGARSS.2008.4779000.

Munk, W., Armi, L., Fischer, K., \& Zachariasen, F. (2000). Spirals on the sea. Proceedings of the Royal Society A: Mathematical, Physical and Engineering Sciences, 456(1997), 1217-1280. https://doi.org/10.1098/ rspa. 2000.0560

Myasoedov, A. (2010). Sunglitter Imagery of the Ocean Surface Phenomena, (48). Retrieved from http://www.nersc.no/ sites/www.nersc.no/files/SUNGLITTER IMAGERY OF THE OCEAN SURFACE PHENOMENA.pdf

Ningsih, N. S., Rahmayani, R., Hadi, S., \& Brojonegoro, I. S. (2008). Internal Waves Dynamics in the Lombok Strait Studied By a Numerical Model. International Journal of Remote Sensing And Earth Sciences, 5, 17-33.

Osadchiev, A. A. (2018). Small Mountainous Rivers Generate High-Frequency Internal Waves in Coastal Ocean. Nature Scientific reports. 8:16609. DOI:10.1038/s41598018-35070-7.

Porter, D. L., \& Thompson, D. R. (1999). Continental shelf parameters inferred from SAR internal wave observations. Journal of Atmospheric and Oceanic Technology, 16(4), 475-487.

Sawyer, C. (1983). A Satellite Study of Ocean Internal Waves. Pac. Mar. Environ. Lab., Seattle, Wash. https://doi. org/10.1108/CG-06-2013-0073.

Susanto, R. D., Mitnik, L., \& Zheng, Q. (2005). Ocean Internal Waves Observed in the Lombok Strait. Oceanography, 18(4), 80-87.

Zanter, K. (2015). Landsat 8 (L8) Data User Handbook Version 1.0. EROS. South Dakota. 